\title{
Day-by-day home-measured blood pressure variability: another important factor in hypertension with diabetic nephropathy?
}

\author{
Kouichi Tamura, Kengo Azushima and Satoshi Umemura \\ Hypertension Research (2011) 34, 1249-1250; doi:10.1038/hr.2011.149; published online 25 August 2011
}

$\mathrm{T}_{\mathrm{i}}^{\mathrm{h}}$

he number of patients with diabetes is

increasing, and cardiovascular complications are the most common cause of death in these patients. Thus, it would be of considerable value to identify the mechanisms involved in the cardiovascular events associated with diabetes. Ambulatory blood pressure (BP) monitoring has allowed an easier and more accurate determination of the circadian rhythm of BP under different pathophysiological conditions. The circadian pattern of BP in patients with diabetes has been found to exhibit a blunted nocturnal decrease in BP, which is associated with autonomic neuropathy and nephropathy. ${ }^{1}$ The loss of nocturnal BP dipping has been considered a risk factor for the progression of nephropathy and of prognostic value with respect to target organ damage and cardiovascular morbidity in both diabetic and hypertensive patients. ${ }^{2-4}$

Ambulatory BP monitoring allows the acquisition of valuable information on not only the average 24-h BP but also the variations in the BP values that happen during the course of daily life. Previous studies on ambulatory BP monitoring have shown that $\mathrm{BP}$ variability is a complex phenomenon that involves both short- and long-lasting changes. Thus, the 24-h BP varies not only because of a reduction in $\mathrm{BP}$ during nighttime sleep and an increase in the morning, but also because of sudden, rapid and short-lasting changes that occur during the daytime and, to a lesser extent, at night. This phenomenon

Dr K Tamura, K Azushima and S Umemura are at the Department of Medical Science and Cardiorenal Medicine, Yokohama City University Graduate School of Medicine, 3-9 Fukuura, Kanazawa-ku, Yokohama 2360004, Japan.

E-mail: tamukou@med.yokohama-cu.ac.jp of short-term BP variability has been shown to depend on sympathetic vascular modulation and on atherosclerotic vascular changes. ${ }^{5}$ Several previous animal studies have shown that exaggerated short-term BP variability without significant changes in mean BP induced chronic cardiovascular inflammation and remodeling (Figure 1). ${ }^{6}$ Short-term BP variability is also thought to be clinically relevant because hypertensive patients with similar 24-h mean BP values exhibit more severe organ damage when the short-term BP variability is greater. ${ }^{5,7-13}$

Several clinical studies have provided epidemiological evidence of the greater accuracy of home BP monitoring compared with clinical BP monitoring for the prognosis of fatal and non-fatal cardiovascular disease in longterm follow-up surveys and in cross-sectional studies. There is a general consensus that home BP monitoring is more convenient, available and less costly than ambulatory BP monitoring, but the superiority of ambulatory BP monitoring for special clinical problems is also clearly recognized. These special clinical problems include (1) the detection of non-dippers or the need for sleep pressures in chronic renal disease, autonomic neuropathies and sleep apnea and (2) the estimation of short-term BP variability. ${ }^{14}$ Surveys of both physicians and patients suggest that home BP monitoring is both appreciated and recognized as a valuable strategy. Several experts in the field of hypertension research and care have published appeals to expand the use of home BP monitoring for routine care and to have it supported by health care systems.

In the current issue of Hypertension Research, Ushigome et al. ${ }^{15}$ evaluated the association of home-measured BP variability with overt nephropathy by a cross-sectional analysis in 858 Japanese patients with type 2 diabetes. The patients measured their BP three times every morning and three times every evening for 2 weeks. The homemeasured BP variability was expressed as the day-by-day BP variability calculated using the within individual coefficient of variation of all home BP values. The dayby-day BP variability in the morning and that in the evening were calculated separately. The authors showed that the day-by-day BP variability correlated with macroalbuminuria (urine albumin-to-creatinine ratio $\geqslant 300 \mathrm{mg} \mathrm{g}^{-1}$ creatinine) independent of the known risk factors in Japanese patients with type 2 diabetes. Concerning home-measured BP variability, a previous study showed that high day-by-day BP variability is associated with increases in total, cardiovascular and stroke mortality, independent of BP value and other cardiovascular risk factors in the general population of the Ohasama study. ${ }^{16}$ For type 2 diabetes, while high short-term BP variability during ambulatory BP monitoring is reported to be associated with atherosclerosis and proteinuria in hypertensive patients with type 2 diabetes, ${ }^{8,17,18}$ the study by Ushigome et al. adds further information about the clinical relevance of home-measured BP variability in the pathophysiology of diabetic nephropathy. Although the hypothesis that home-measured BP variability favors the development of nephropathy in type 2 diabetes is appealing, the cross-sectional nature of this study makes it impossible to evaluate the causal relationships between dayby-day BP variability and diabetic nephropathy, as acknowledged by the authors. ${ }^{15}$ Further studies, such as outcome studies focusing on whether a therapeutic intervention 


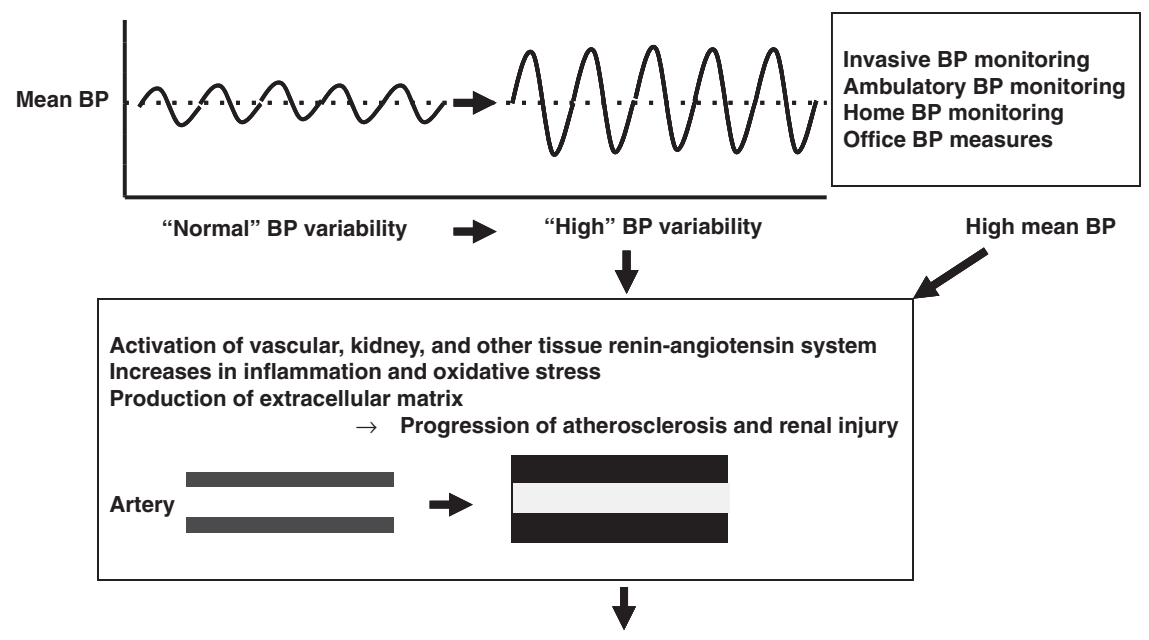

Development of target organ damage

(cardiovascular disease and renal deterioration)

Figure 1 Schema showing the proposed effects of BP variability by various BP measures on the progression of vascular atherosclerosis and the development of target organ damage.

that reduces day-by-day BP variability also carries additional prognostic benefits through the concomitant suppression of the development of diabetic nephropathy, are warranted to confirm the prognostic value of homemeasured BP variability.

\section{CONFLICT OF INTEREST}

The authors declare no conflict of interest.

1 Spallone V, Bernardi L, Ricordi L, Solda P, Maiello MR, Calciati A, Gambardella S, Fratino P, Menzinger G. Relationship between the circadian rhythms of blood pressure and sympathovagal balance in diabetic autonomic neuropathy. Diabetes 1993; 42: 1745-1752.

2 Nakano S, Fukuda M, Hotta F, Ito T, Ishii T, Kitazawa M, Nishizawa M, Kigoshi T, Uchida K. Reversed circadian blood pressure rhythm is associated with occurrences of both fatal and nonfatal vascular events in NIDDM subjects. Diabetes 1998; 47: 1501-1506.

3 Sturrock ND, George E, Pound N, Stevenson J, Peck GM, Sowter H. Non-dipping circadian blood pressure and renal impairment are associated with increased mortality in diabetes mellitus. Diabet Med 2000; 17: 360-364.

4 Palmas W, Pickering TG, Teresi J, Schwartz JE, Moran A, Weinstock RS, Shea S. Ambulatory blood pressure monitoring and all-cause mortality in elderly people with diabetes mellitus. Hypertension 2009; 53: 120-127.

5 Tamura K, Tsurumi Y, Sakai M, Tanaka Y, Okano Y, Yamauchi J, Ishigami T, Kihara M, Hirawa N, Toya $Y$, Yabana M, Tokita Y, Ohnishi T, Umemura S. A possible relationship of nocturnal blood pressure variability with coronary artery disease in diabetic nephropathy. Clin Exp Hypertens 2007; 29: 31-42.
6 Kudo $\mathrm{H}$, Kai H, Kajimoto H, Koga M, Takayama N, Mori T, Ikeda A, Yasuoka S, Anegawa T, Mifune H, Kato S, Hirooka Y, Imaizumi T. Exaggerated blood pressure variability superimposed on hypertension aggravates cardiac remodeling in rats via angiotensin II systemmediated chronic inflammation. Hypertension 2009; 54: 832-838.

7 Eguchi K, Ishikawa J, Hoshide S, Pickering TG, Schwartz JE, Shimada K, Kario K. Night time blood pressure variability is a strong predictor for cardiovascular events in patients with type 2 diabetes. Am J Hypertens 2009; 22: 46-51.

8 Masuda S, Tamura K, Wakui H, Kanaoka T, Ohsawa M, Maeda A, Dejima T, Yanagi M, Azuma K, Umemura S. Effects of angiotensin II type 1 receptor blocker on ambulatory blood pressure variability in hypertensive patients with overt diabetic nephropathy. Hypertens Res 2009; 32: 950-955.

9 Mitsuhashi H, Tamura K, Yamauchi J, Ozawa M, Yanagi M, Dejima T, Wakui H, Masuda SI, Azuma K, Kanaoka T, Ohsawa M, Maeda A, Tsurumi-Ikeya $Y$, Okano $Y$, Ishigami T, Toya Y, Tokita Y, Ohnishi T, Umemura S. Effect of losartan on ambulatory short-term blood pressure variability and cardiovascular remodeling in hypertensive patients on hemodialysis. Atherosclerosis 2009; 207: 186-190.

10 Ozawa M, Tamura K, Okano Y, Matsushita K, Ikeya Y, Masuda S, Wakui H, Dejima T, Shigenaga A, Azuma K, Ishigami T, Toya Y, Ishikawa T, Umemura S. Blood pressure variability as well as blood pressure level is important for left ventricular hypertrophy and brachialankle pulse wave velocity in hypertensives. Clin Exp Hypertens 2009; 31: 669-679.

11 Rothwell PM. Limitations of the usual bloodpressure hypothesis and importance of variability, instability, and episodic hypertension. Lancet 2010; 375: 938-948.

12 Shigenaga A, Tamura K, Dejima T, Ozawa M, Wakui H, Masuda S, Azuma K, Tsurumi-Ikeya Y, Mitsuhashi H, Okano Y, Kokuho T, Sugano T, Ishigami T, Toya Y, Uchino K, Tokita Y, Umemura S. Effects of angiotensin II type 1 receptor blocker on blood pressure variability and cardiovascular remodeling in hypertensive patients on chronic peritoneal dialysis. Nephron Clin Pract 2009; 112: c31-c40.

13 Shintani Y, Kikuya M, Hara A, Ohkubo T, Metoki H, Asayama K, Inoue R, Obara T, Aono Y, Hashimoto T, Hashimoto J, Totsune K, Hoshi H, Satoh H, Imai Y. Ambulatory blood pressure, blood pressure variability and the prevalence of carotid artery alteration: the Ohasama study. J Hypertens 2007; 25: 1704-1710.

14 Bilo G, Parati G. Rate of blood pressure changes assessed by $24 \mathrm{~h}$ ambulatory blood pressure monitoring: another meaningful index of blood pressure variability? J Hypertens 2011; 29: 1054-1058.

15 Ushigome E, Fukui M, Hamaguchi M, Senmaru T, Sakabe K, Tanaka M, Yamazaki M, Hasegawa G, Nakamura N. The coefficient variation of home blood pressure is a novel factor associated with macroalbuminuria in type 2 diabetes mellitus. Hypertens Res 2011; 34: 1271-1275.

16 Kikuya M, Ohkubo T, Metoki H, Asayama K, Hara A, Obara T, Inoue R, Hoshi H, Hashimoto J, Totsune K, Satoh H, Imai Y. Day-by-day variability of blood pressure and heart rate at home as a novel predictor of prognosis: the Ohasama study. Hypertension 2008; 52 : 1045-1050.

17 Ozawa M, Tamura K, Okano Y, Matsushita K, Yanagi M, Tsurumi-Ikeya Y, Oshikawa J, Hashimoto T, Masuda S, Wakui H, Shigenaga A, Azuma K, Ishigami T, Toya $Y$, Ishikawa T, Umemura S. Identification of an increased short-term blood pressure variability on ambulatory blood pressure monitoring as a coronary risk factor in diabetic hypertensives. Clin Exp Hypertens 2009; 31: 259-270.

18 Kanaoka T, Tamura K, Moriya T, Tanaka K, Konno Y, Kondoh S, Toyoda M, Umezono T, Fujikawa T, Ohsawa M, Dejima T, Maeda A, Wakui H, Haku S, Yanagi M, Mitsuhashi H, Ozawa M, Okano Y, Ogawa N, Yamakawa T, Mizushima S, Suzuki D, Umemura S. Effects of multiple factorial intervention on ambulatory BP profile and renal function in hypertensive type 2 diabetic patients with overt nephropathy-a pilot study. Clin Exp Hypertens 2011; 33: 255-263. 